\title{
Assessment of direct and indirect effects of building developments on the environment
}

https://doi.org/10.1515/eng-2019-0013

Received September 4, 2018; accepted January 2, 2019

\begin{abstract}
Any building construction undertaking is inseparable from the environment in which it will be executed. Among all buildings, the most difficult ones from the point of view of nature protection are those which have been classified as having a considerable impact on the environment. Roads and road infrastructure are a particular case. Construction of roads or railroads and their subsequent long-term use lead to many changes in the environment. When planning such building projects, it is recommended to develop variant solutions in order to choose the one that would be least harmful to the environment, and then to submit them to an objective assessment. To facilitate the selection of an optimal solution, assessment indicators are developed. However, it needs to be remembered that a factor perceived as a negative one in the immediate assessment might generate positive consequences on a broader scale and vice versa. Hence, an assessment of the impacts on the environment caused by building projects should be viewed in the context of indirect (global) and direct (local) effects. This article will present a model analysis of the impacts caused by a fragment of a road, including local and global effects measured by the indicator method. This method has been developed by the author of this article, who believes that it enables the user to make a complex analysis, while the graphic presentation it involves, discussed in the conclusions to this paper, helps to decide easily which factors are decisive in the final assessment of the analysed project.
\end{abstract}

Keywords: direct and indirect impact, environmental protection, building investment

\footnotetext{
^Corresponding Author: Elżbieta Hanna Szafranko: Faculty of Geodesy, Geospatial and Civil Engineering, University of Warmia and Mazury in Olsztyn, 10 - 724 Olsztyn, Heweliusza 4 Str., Poland; E-mail: elasz@uwm.edu.pl
}

\section{Introduction}

Building projects, when executed, are responsible for lesser or greater impacts on the environment. Some impacts may not be positive. The construction process and the subsequent use of a building structure can impose an imprint on the nearest surroundings. Emission of pollution [1], noise and other interferences due to the use of a civil engineering construction can be mitigated by its proper design, employment of eco-friendly technologies [2] or resourceful solutions for its future operation. Among a variety of buildings, special attention should be paid to the ones which are designated by law as having considerable impact on the environment. Road building projects [3] are particularly interesting because of the way roads are used. Roads can run for miles on end, intersecting diverse areas, including ones that are valuable for the environment $[4,5]$. Moreover, because of their size and function, roads generate impacts which are received in the immediate environs, and therefore seen as local ones, as well as indirect impacts, of a much broader range, including global effects. Such impacts can include the distorted hydrological balance due to inadequate engineering solutions applied to water crossing systems, or interference with animal migration routes, which can stretch for hundreds of miles. These are the reasons why plans to build a new road ought to be developed in several variants, which above all take into consideration nature protection. The diversity of problems connected with the execution of a road development plan makes it a challenging task $[6,7]$.

\section{Materials and methods}

Identification of the optimal variant solution of a building project will largely depend on the proper definition and appraisal of assessment criteria. Criteria may have different character. Overall, the criteria applied in an assessment of a building project are divided into hard (barriers) and soft ones (factors, parameters) [8]. Depending on the aspect they describe, they can be expressed in a measurable $(\mathrm{km}$, 
tons, items, etc.) or immeasurable way (e.g. impact on the environment, formal and legal conditions, social effects, etc.). Soft criteria are most often the subject of analyses, and they are connected with the phenomena which can be graded in their description. Soft criteria can be presented descriptively or by assigning weighted scores for meeting specific requirements. Examples of soft criteria are: distance to a public road (in $\mathrm{km}$ ), distance to water bodies $(\mathrm{km})$, number of trees to be cut down (items).

Soft criteria, known as factors, lend themselves to being evaluated on a scale showing the degree to which they satisfy requirements, and therefore can be presented in tables or on maps of the fulfilment of individual criteria by the analysed variants. An analysis of a road development project is most often made on the basis of environmental criteria, which take into account different aspects of the relationship between the project and the surroundings. The criterion of the environment protection most often comprises subcriteria which evaluate the consequences of intersecting watercourses, the length of a road section passing through nature valuable areas or nature habitats which could be destroyed, intersecting animal migration routes, volume of the emission of hazardous substances, number of trees to be felled. When making an assessment of the project's impact on the environment [9], we encounter many aspects which can be assigned negative values. When an environmental impact assessment concerns a large-size building project, it is important to take into account their impact in both a closer and a broader view. This is extremely important because, depending on the applied assessment scale, the achieved results may vary. An assessment procedure involves groups of experts selected from various backgrounds. The expected local impact of a building project is assessed by representatives of the local community and of the offices which are administratively attached to a given territory. On a broader scale, the conditions are analysed by representatives of organisations dealing with nature conservation and of higher-rank administration offices. Experts work according to two procedures. One consists of collaborative efforts while evaluating the criteria within the analysed group of parameters. By exchanging their opinions, experts assign importance (weights) or evaluate the impact on the attainment of the set goal. The other procedure relies on well-prepared surveys, composed of tables, where experts work separately from one another and assign scores according to the superimposed scale. The results need further processing and may have to be supplemented. However, it might also happen than due to the lack of cohesion among the acquired opinions, the whole survey will have to be repeated [10].
The next step in the analytical process involved determination of the importance of the previously described criteria in the context of the project during its performance, again in the narrow and broader approaches. Weights define priorities, which can be satisfied to different degrees by the designed variants.

The indicator method, which the author developed on the basis of the Polish guidelines set for evaluation of variants in road development projects, has been applied to make a comprehensive assessment of a model development plan [11]. This method employs matrices (constructed as tables), in which particular environmental impacts are described and subsequent criteria are assigned weights (significant of an impact on the environment). Specification of all data we are interested in encompasses all analysed variants of the localisation of the planned road. Table 1 illustrates the principles of constructing a matrix. The number in the upper left-hand corner describes the immediate effect and the one in the bottom right-hand corner refers to the indirect effect on a given component of the natural environment. The number in the centre is the sum of effects multiplied by their weight. The sum of individual effects is the assessment of the impact on the environment caused by the analysed variant.

The assessment on the effect of the $\mathrm{j}^{\text {th }}$ variant on the $\mathrm{i}^{\text {th }}$ criterion [11]:

$$
Q i j=\left(P_{i j}+R_{i j}\right) \cdot W_{i}
$$

where:

$\mathrm{P}_{i j}$ - direct effect of a subsequent variant,

$\mathrm{R}_{i j}$ - indirect effect of a subsequent variant,

$\mathrm{W}_{i}$ - weight of criterion $\mathrm{A}$.

Example of descriptive scale of factor A4 evaluation is presented in Table 2 and the weight rating scale it is presented in Table 3.

\section{Case study}

To illustrate the issues associated with an assessment of a building investment made according to the approach presented above, three variants of a road development were analysed. Based on an analysis of other projects conducted in the same region, which is distinguished by highly valuable nature assets, and in line with experts' opinions, the following criteria were identified as the most common in an evaluation of environmental factors, denoted the symbol A:

A1 - problems due to emission of noise, A2 - problems due to emission of pollutants, 
Table 1: Table with calculation fields

\begin{tabular}{lc|cc|cc|cc|ccc|c}
\hline No & $\begin{array}{c}\text { Analysed } \\
\text { criterion }\end{array}$ & \multicolumn{3}{|c|}{$\begin{array}{c}\text { Variant } \\
\mathrm{nr} 1\end{array}$} & \multicolumn{3}{c|}{$\begin{array}{c}\text { Variant } \\
\mathrm{nr} 2\end{array}$} & \multicolumn{3}{c|}{$\begin{array}{c}\text { Variant } \\
\mathrm{nr} 3\end{array}$} & $\begin{array}{c}\text { Weight of } \\
\text { criterion }\end{array}$ \\
\hline 1 & $\mathrm{~A} 1$ & $\mathrm{P}_{11}$ & $\mathrm{Q}_{11}$ & $\mathrm{R}_{11}$ & $\mathrm{P}_{12}$ & $\mathrm{Q}_{12}$ & $\mathrm{R}_{12}$ & $\mathrm{P}_{13}$ & $\mathrm{Q}_{13}$ & $\mathrm{R}_{13}$ & $\mathrm{~W}_{1}$ \\
2 & $\mathrm{~A} 2$ & $\mathrm{P}_{21}$ & $\mathrm{Q}_{21}$ & $\mathrm{R}_{21}$ & $\mathrm{P}_{22}$ & $\mathrm{Q}_{22}$ & $\mathrm{R}_{22}$ & $\mathrm{P}_{23}$ & $\mathrm{Q}_{23}$ & $\mathrm{R}_{23}$ & $\mathrm{~W}_{2}$ \\
3 & $\mathrm{An}$ & $\cdots$ & $\cdots$ & $\cdots$ & $\cdots$ & $\cdots$ & $\cdots$ & $\cdots$ & $\cdots$ & $\cdots$ & $\cdots$ \\
\hline
\end{tabular}

Table 2: The descriptive scale of assessment for factor A4 based on [11, 12]

\begin{tabular}{|c|c|c|}
\hline No & $\begin{array}{l}\text { Weights - } \\
\text { punctation }\end{array}$ & Description of criterion A1 \\
\hline 1 & 3 & $\begin{array}{l}\text { The road does not cross migration routes of animals not registered adverse } \\
\text { impacts }\end{array}$ \\
\hline 2 & 2 & $\begin{array}{l}\text { The route crosses the few animal migration routes and the effects of the } \\
\text { implementation are eliminated by well-designed animals passages }\end{array}$ \\
\hline 3 & 1 & $\begin{array}{l}\text { The route crosses the animal migration routes, and most of them are } \\
\text { implemented through animal passages }\end{array}$ \\
\hline 4 & 0 & $\begin{array}{l}\text { The implemented investment crosses the hiking routes. It makes the transition of } \\
\text { animals to a small extent difficult. }\end{array}$ \\
\hline 5 & -1 & $\begin{array}{l}\text { The implemented investment creates few problems in overcoming the route for } \\
\text { animals }\end{array}$ \\
\hline 6 & -2 & $\begin{array}{l}\text { The implemented investment creates problems in overcoming the route for } \\
\text { animals and is the cause of the few deaths among animals }\end{array}$ \\
\hline 7 & -3 & $\begin{array}{l}\text { The implemented investment makes it impossible to overcome the route for } \\
\text { animals, it is the cause of many accidents of deadly animals }\end{array}$ \\
\hline
\end{tabular}

A3 - nuisance caused by higher traffic,

A4 - risks caused by intersecting animal migration routes, A5 - consequences of crossing watercourses.

A1 - problems caused by noise emission can be viewed from a broader and a narrow perspective. Building a road in a given site can lead to greater noise in the area directly adjacent to that road. However, a properly planned route can keep noise emission away from protected areas or habitats of valuable animal species. Moreover, an upgrading of a road can make the traffic smoother and consequently reduce the noise from motor traffic over a larger area. When planning a section of a road passing through nature protected areas, an effective solution is to design noise barriers which limit the propagation of sound waves.

A2 - Issues related to the emission of pollutants include discharge of gaseous and liquid substances as well as dumping litter in areas adjacent to the road. A way to reduce the risk caused by traffic participants may be by erecting structures limiting the penetration of harmful substances off the road, and by building well-designed service areas. stops. Of course, it is equally important to plan the route properly so that it bypasses the most valuable areas.

A3 - Nuisance related to traffic intensity can be viewed from different angles. On the one hand, the development of a road network easies the traffic congestion and reduces the nuisance due to intensive traffic over a larger area; on the other hand, it can transfer the burden of motor transportation to other road sections. Hence, this negative impact can be reduced in one area but intensified it somewhere else.

A4 - Threats arising from the interference with animal migration routes occur whenever roads pass through densely afforested areas. The best method of reducing negative effects is by making an effort to bypass such areas and avoid the crossing of animal migration routes. However, it is not always possible. Another effective solution is to develop well-designed animal passages. Attempts are also made to correct routes and to guide animals to safe routes that coincide with migration directions.

A5 - The intersection of watercourses can have various effects. On the one hand, it affects the ecosystems and be- 
Table 3: The weight rating scale and preference vector

\begin{tabular}{cccc}
\hline No & Factor & Weight of factor & Preference vector \\
\hline 1 & A1 & 1 & 0,11 \\
2 & A2 & 1 & 0,11 \\
3 & A3 & 2 & 0,22 \\
4 & A4 & 3 & 0,33 \\
5 & A5 & 2 & 0,22 \\
\hline & Sum & 9 & 1 \\
\hline
\end{tabular}

haviour of animals whose lives are connected with specific bodies of water. On the other hand, it can distort the water management over a large area. Poorly designed culverts or river crossings can result in a significant raising or lowering of water levels in water bodies, and therefore disturb the hydrological balance.

All the described factors may affect the immediate and more distant surroundings, and whether or not they are perceived as negative direct and indirect effects is essential for proper investment planning. Well-chosen routes or roads to be built, taking into account all aspects of the construction and operation of road structures, can reduce negative impacts to a minimum.

Three variant routes of a new road have been considered in the analysed case:

Variant 1 - It fulfils the environmental and spatial requirements to the highest degree, satisfies the transportation requirements to a slight degree and is the least economical. This is a longer route which circumnavigates several environmental collisions and has the shortest sections passing through the forest areas.

Variant 2 - It is the least expensive variant, in terms of both the cost of construction works and the cost of the purchase of land. It satisfies transportation criteria, only partly fulfils environmental criteria, intersects protected areas and animal migration routes. Moreover, it passes near habitats of protected species. The route is the shortest but does not completely satisfy the transportation and environmental expectations.

Variant 3 - It is best at meeting transportation criteria and design requirements concerning the planning of routes of roads and other construction-related conditions, economically it is better than 1 but worse than 2, it partly satisfies environmental conditions, and it crosses the highest number of watercourses.

In the first part of the research, experts appointed to make the assessment estimated the importance of factors related to the environmental evaluation of a construction project. At the next stage, they expressed their opinions on the developed variants by completing previously pre- pared questionnaires investigating the risk of negative impacts in a closer and broader sense. The evaluation included three variants (based on a complete description of the investment). The results of the research are presented in Table 4.

The evaluation of the variants takes into account possible negative effects of environmental impacts, and in one case the final result is also negative. Variant 1, which envisages a route avoiding environmental collisions and afforested areas, was assessed the highest. The lowest score was assigned to Variant 2, crossing through protected areas and animal migration routes, as well as posing a threat to habitats of protected species.

\section{Results and discussion}

The obtained results and their analysis provide us with answers to many questions related to the selection of a performance variant of the planned new road.

Having scrutinised the performed survey and calculations, it can be concluded that the final result of the assessment is most heavily influenced by the way the analysed variants fulfilled factor A4 - threats posed by intersecting animal migration routes. It is the variant which trespasses protected areas and intersects animal migration routes that scored the lowest. Both the partial and the final assessment indicate that this is the problem that poses the gravest risk to the environment (Fig. 1).

Problems due to emission of noise - factor A1 and problems due to emission of pollutants - A2, are met at a similar level for all the variants under consideration and their impact on the final assessment is small (Fig. 1).

A3 - nuisance caused by higher traffic, this is the only factor that has different characteristics. It is met at the highest level by an intermediate solution - variant V3 (Fig. 1).

The course of the lines (Fig. 1) illustrating the accumulated effect of impacts on the environment produced by the 
Table 4: Results of the research

\begin{tabular}{cc|ccc|ccc|ccc|c}
\hline No & $\begin{array}{c}\text { Analysed } \\
\text { criterion }\end{array}$ & \multicolumn{3}{|c|}{ Variant 1 } & \multicolumn{3}{|c|}{ Variant 2 } & \multicolumn{3}{|c|}{ Variant 3 } & $\begin{array}{c}\text { Weights of } \\
\text { criteria }\end{array}$ \\
\hline 1 & A1 & -1 & 1 & 2 & -3 & -5 & -2 & -1 & -2 & -1 & 1 \\
2 & A2 & -1 & 2 & 3 & -2 & -2 & 0 & -1 & 2 & 3 & 1 \\
3 & A3 & -2 & -2 & 1 & -1 & 2 & 2 & 2 & 10 & 3 & 2 \\
4 & A4 & 3 & 18 & 3 & -2 & -12 & -2 & 0 & 3 & 1 & 3 \\
5 & A5 & 2 & 8 & 2 & -1 & 0 & 1 & -1 & -8 & -3 & 2 \\
\hline
\end{tabular}

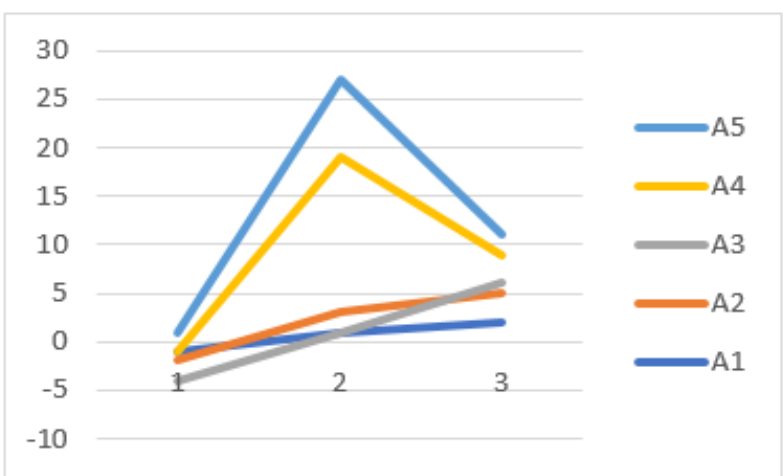

(a) Top rated variant $\mathrm{V} 1$

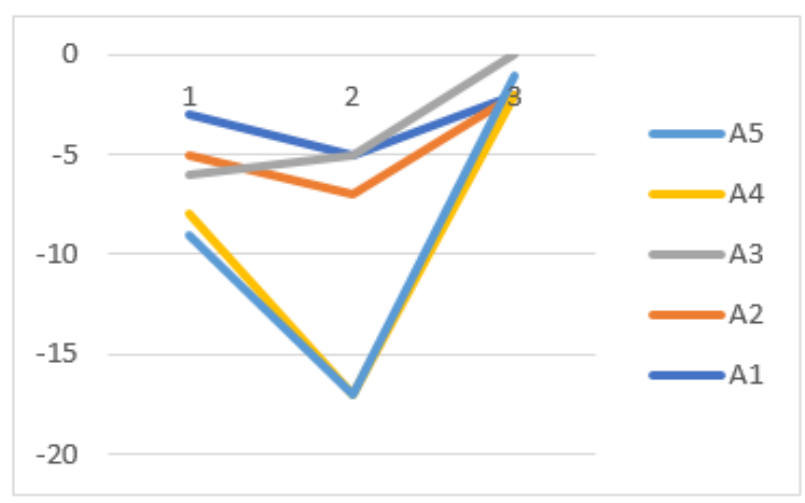

(b) The worst rated variant V2

Figure 1: Diagrams illustrated evaluation of the best and worst variants

variants suggests that the final assessment is most strongly affected by the fulfilment of factor A4. On the left-hand side of the diagram we can see the evaluation of impacts on the local scale (direct impact), while the right-hand side shows the same information on a wider, global scale (indirect effect). It is possible to notice that in both the best and the worst solution the direct effects are felt more painfully and scored lower values in the assessment (Fig. 1).

Regarding the environmental criterions and impact on the environment and environmental protection, we can see that broader (indirect) effects are notice by experts as nearly less harmful to the environment than the direct impact (especially in the immediate vicinity of the planned road) and evaluated higher by the experts. For many subcriteria, the direct effects are far more often assessed as negative ones.

\section{Conclusion}

An analysis of road development plants always provides a wealth of data on the planned investment project as well as possible problems caused by its implementation and later use. The example presented in this paper documents an analysis of three variants, and the factors included as assessment criteria were chosen on the basis of opinions expressed by experts as the ones which are most frequently used in producing variant solution of road development projects. These are environmental criteria and it is mandatory to determine whether a planned road satisfies them if it is to run through nature valuable areas. This study implicates that the final assessment is most strongly affected by the results of an analysis pertaining to threats due to intersecting animal migration routes. This problem is also the hardest to solve. The data and calculations presented in this article are just a fragment of a larger study, yet they confirm the need to conduct analyses of variant solutions of a planned road, and prove that the inclusion of both direct and indirect effects provides a deeper insight into the planned construction undertaking.

\section{References}

[1] Shen, L. Y., Li Hao, J., Tam, V. W. Y., \& Yao, H. A checklist for assessing sustainability performance of construction projects, Journal of civil engineering and management, 2007, 13(4), 273-281 
[2] Kazmi, M. S., Munir, M. J., Abbas, S., Saleem, M. A., Khitab, A., \& Rizwan, M. Development of lighter and eco-friendly burnt clay bricks incorporating sugarcane bagasse ash. Pakistan Journal of Engineering and Applied Sciences, 2017, 1-5

[3] Bernold, L. E., Lee, T. S., Koo, J. K., \& Moon, D. S. Automated ecofriendly road stripe removal system. Automation in Construction, 2010, 19(6), 694-701

[4] Lehmann, S. Green urbanism: Formulating a series of holistic principles. SAPIENS. Surveys and Perspectives Integrating Environment and Society, 2010, 3(2), 1-51

[5] Garcia, D. A., Cumo, F., Sforzini, V., \& Albo, A. Eco friendly service buildings and facilities for sustainable tourism and environmental awareness in protected areas. WIT Transactions on Ecology and the Environment, 2012, 161, 323-330.

[6] Borgonovo, E., \& Peccati, L. Uncertainty and global sensitivity analysis in the evaluation of investment projects. International Journal of Production Economics, 2006, 104(1), 62-73.
[7] Szafranko, E. Application of Multi-Criterial Analytical Methods for Ranking Environmental Criteria in an Assessment of a Development Project. Journal of Ecological Engineering, 2017, 18(5), 151-159

[8] Sclove, S. L. Application of model-selection criteria to some problems in multivariate analysis. Psychometrika, 1987, 52(3), 333-343

[9] Mehta, K. P. Reducing the environmental impact of concrete. Concrete international, 2001, 23(10), 61-66

[10] Szafranko, E. H., \& Harasymiuk, JEvaluation of the impact of public investments on the environment on the example of stadium implementation. Inżynieria Ekologiczna, 2017, 18(5), 5865

[11] Szafranko, E. Applicability of the indicator method to evaluation of road building projects. News in Engineering, 2015, 1, 1-9

[12] Aikhuele, D. O., \& Turan, F. M., An exponential-related function for decision-making in engineering and management. Open Engineering, 2017, 7(1), 153-160 